\title{
A ocupação dos sertões no século XVIII. O caso do oeste baiano
}

Adriano Bittencourt Andrade*

\section{Resumo}

O texto que segue objetiva apresentar, sob o aporte da Cartografia Histórica, dados e análises que revelem, no século XVIII, a incipiente ocupação do atual Oeste baiano, naquele tempo uma região genericamente tratada como "sertões" assim como todo o território interior ainda carente de um efetivo povoamento pelo agente colonizador. A primeira seção faz análise do tempo e espaço estudado, desenvolve a seguir uma avaliação comparada entre os sertões e litoral tomando como referenciais a ocupação e o uso do espaço e, após apresentar uma breve evolução políticoadministrativa de alguns municípios da região, o texto trata da parca ocupação do Oeste baiano setecentista à luz das incipientes formações urbanas lá estabelecidas (vilas, povoados, pousos, aldeias) que exerciam o papel de "chaves" do território - núcleos de uma dispersa rede que sediavam o poder político-administrativo sobre vastos termos - notadamente no tocante ao controle sobre os caminhos de gado ou para as minas. Na última seção escreve-se sobre a configuração espacial da margem esquerda do rio São Francisco a partir da observação crítica de mapas da cartografia histórica. Este escrito procura revelar eventos e assim dar visibilidade a um conhecimento histórico mais amplo sobre a configuração do atual espaço brasileiro e baiano.

Palavras-chave: Geografia Histórica; Século XVIII; Sertões; Oeste da Bahia.

Universidade Federal da Bahia (abittandrade @ hotmail.com).

Geosul, Florianópolis, v. 28, n. 55, p 77-102, jan./jun. 2013 
ANDRADE, A.B. A ocupação dos sertões no século XVIII. O caso do...

The occupation of the "sertões" in the eighteenth century. The case of baiano western

\section{Abstract}

The following text aims to present, under the Historical Cartography, data and analysis that reveal, in the 18th century, the incipient occupation of the current west Baiano, at that time a region treated generically as "sertões" as in all the interior territory yet in need of a settlement by the colonizer agent. The first section analyzes the time and studied space, it is developed next a compared evaluation between the Sertões and the Seashore taking as a references the occupation and the use of the space and, after presenting a brief evolution political/administrative of some counties of the region, the text discusses about the very few West Baiano occupation in the $\mathrm{d} 17$ th century considering the beginnings urban formation established there (villages, settlement) that had the role of "keys" of the territories - nuclei of the a disperse net that hosted the administrative-political power on vast terms - especially on the control of the cattle way or to the mines. The last section is about São Francisco left riverbank spatial configuration from the critical observation of the historical cartography. This text searched to reveal the events and so give visibility to an ample historical knowledge on the present Brazilian and Baiano space configuration.

Key words: Historical Geography; 18th Century; "Sertões"; West of Bahia.

\section{Introdução}

Nas últimas décadas houve uma significativa ampliação dos estudos historiográficos de base documental, isso se deu como decorrência da maior acessibilidade aos fundos de arquivos anteriormente restritos, notadamente os portugueses, bem como da expansão de cursos de pós-graduação e consolidação de áreas 
ANDRADE, A.B. A ocupação dos sertões no século XVIII. O caso do...

específicas como a Geografia Histórica (tanto nas abordagens urbanas como regionais). Esse fato possibilita um olhar mais amplo sobre as estruturas espaciais pretéritas, o desvelar de eventos até então obscuros ou omitidos na historiografia oficial e, distanciando-se de um entendimento cronológico linear da história, o conhecer acerca de dinâmicas passadas que pode trazer como repercussões uma ação concreta sobre o espaço construído.

$\mathrm{O}$ texto que segue adensa o rol desses trabalhos embasados nos constructos da Geografia Histórica. A partir de uma ampla temática regional - as dinâmicas espaciais do Oeste baiano busca-se neste escrito mapear e entender como se deu a ocupação e o uso do território estudado no percurso do século XVIII. É uma tentativa de unir voz à Nova História, sem a preocupação precípua de negar o dito, mas de dizer coisas novas a partir da avaliação de outros eventos pouco "iluminados" nos estudos até então feitos.

O Oeste baiano, como se verá a seguir, tem uma história de colonização relativamente recente, derivado de imensos termos das poucas vilas fundadas nos Setecentos e início do século XIX e compondo os genéricos "sertões" entre as capitanias da Bahia, Minas Gerais, Goiás e Pernambuco. A dispersão territorial e dificuldade de acesso aliadas a uma ocupação definitiva da região apenas na segunda metade no século passado, oblitera a oferta de documentação para o século XVIII que normalmente aparece em pequeno número e distribuídos nos arquivos das quatro capitanias supracitadas, além dos fundos do Governo Geral (Salvador e, desde 1763, Rio de Janeiro) e da sede da Coroa (Lisboa/Portugal). Esse óbice, se dificulta a caminhada do pesquisador, amplia a relevância de textos de base primária que analisem os "sertões" sob a perspectiva dos processos e arranjos espaciais decorrentes da ocupação e uso daquele território.

Tem-se então como recorte têmporo-espacial o Oeste baiano no século XVIII, visto que foi neste período que três processos coadunados repercutiram numa ocupação e uso mais efetivo da região: (1) Povoamento e incorporação já efetivados pelos colonizadores na faixa litorânea, notadamente no Recôncavo 
ANDRADE, A.B. A ocupação dos sertões no século XVIII. O caso do...

baiano; (2) Descoberta de minas de ouro nas terras centrais território colonial, num polígono triangular que praticamente circunscrevia o Oeste - as Minas Gerais, terras de Goiás e aquémSão Francisco, na atual Chapada Diamantina -; (3) Criação da primeira vila com sede na região (São Francisco das Chagas da Barra do Rio Grande, em 1752), o que revela o interesse formal de regulação da Coroa sobre o território a partir da instituição de bases urbanas que viriam a se estabelecer em pontos longínquos, porém com controle legalmente constituído sobre vasto espaço.

Utilizou-se na produção deste escrito a pesquisa bibliográfica e documental, esta, especialmente nos fundos do Arquivo Histórico Ultramarino e Torre do Tombo (ambos em Lisboa/Portugal), além da busca por imagens da cartografia histórica em arquivos portugueses e brasileiros, conforme citações no corpo do texto. Estruturou-se o texto em quatro seções além da introdução e considerações finais, quais sejam: (1) "Ajustes conceituais", a necessidade de, ainda que brevemente, tratar dos parâmetros conceituais fundamentais para o entendimento do discurso que segue, especificamente sobre a Geografia e Cartografia Histórica e da aplicação do conceito de urbano para o tempo e espaço em foco; (2) "Sertões, litoral e minas", numa análise comparativa, avalia-se, nesta seção, ocupação e usos destas genéricas regiões do Brasil Setecentista, bem como as necessárias interconexões estabelecidas entre elas; (3) "Evolução administrativa das principais formações urbanas do Oeste baiano", mais que um catálogo, pretende-se nessa seção observar a gênese do urbano na região e a centralidade das recém-criadas vilas na organização e controle do território; (4) "Análise de mapas históricos", uma síntese do discurso anterior expresso, nesta seção, na produção cartográfica do período.

Ratifica-se ainda em termos introdutórios que não é possível estudar o Oeste colonial como uma unidade absolutamente autônoma e hermética, mesmo considerando a ausência de uma rede urbana nacional e o distanciamento dos núcleos povoados que isolava pessoas e relações, havia um projeto colonizador e uma 
ANDRADE, A.B. A ocupação dos sertões no século XVIII. O caso do...

série de decisões hierárquicas e centralizadas que articulava e determinava usos no território conquistado. Essa é uma premissa para o discurso que segue. Por isso o uso de nomenclaturas aproximadas para tratar da área.

Faz-se necessário então essa diferenciação como um esclarecimento acerca do recorte espacial visto que Oeste baiano, Sertões da Bahia e Além-São Francisco não dizem respeito à mesma área, como se viu anteriormente, os sertões possuíam a amplitude do desconhecimento do território, era sertão o espaço a ser ocupado e colonizado, daí poder-se tratar do sertão de Cachoeira e dos sertões do Piauí, muito mais uma generalidade social que uma região geográfica definida. O Oeste baiano responde ao que acima indicamos como mesorregião do Extremo Oeste baiano, composto pelas microrregiões de Barreiras, Cotegipe e Santa Maria da Vitória, um espaço restrito e relativo a nossa contemporaneidade e aos atuais limites políticos. O Além-São Francisco, talvez seja o termo mais adequado para tratar da região no período colonial visto a precisão deste leito hídrico na demarcação e alcance do território interior. O Além-São Francisco eram as terras da margem esquerda do curso médio do referido rio que durante quase a totalidade do século XVIII compôs a Comarca do Rio São Francisco, como se verá adiante. No decorrer do texto os três termos serão utilizados de acordo com a amplitude do que se pretende tratar.

\section{Ajustes conceituais}

Conforme referenciado alhures, este é um trabalho da Geografia Histórica, e, como tal, tem o espaço social como objeto de estudo. Busca-se essencialmente a configuração territorial de processos vividos em outros tempos históricos. É uma tentativa de entendimento de dinâmicas espaciais passadas à luz de documentação e cartografia primárias.

A leitura de textos produzidos no século XVIII por viajantes ou por outros agentes colonizadores que tem registro arquivado 
ANDRADE, A.B. A ocupação dos sertões no século XVIII. O caso do...

como resultado das comunicações formais entre as escalas hierárquicas do Império Português, revela pistas das formas materiais que compunham uma dada vila mas também o cotidiano dos espaços ocupados o que possibilita uma releitura da história a partir da análise de eventos e dinâmicas próprias de uma grande escala, análises essas normalmente obliteradas nos estudos mais genéricos das escalas menores.

Da mesma forma, a documentação cartográfica, ainda que escassa e predominantemente na escala regional ou continental para o tempo-espaço estudado, se analisada com foco no Oeste, traz informações fundamentais ao entendimento da procurada dinâmica espacial pretérita, a exemplo da malha de caminhos terrestres que cruzava a região e se constituiu, com se verá a seguir, num fixo determinante para a ocupação da área, prioritariamente feita a partir do estabelecimento de pousos nos caminhos dos gados e para as minas.

Parece evidente que documentos históricos, textuais ou cartográficos, guardam inevitáveis parcialidades na sua construção. Os mapas, especificamente, eram além de instrumentos de comunicação, preciosos artefatos para o deslocamento, localização e tomada de posse de um dado território. Cartografar significava conhecer e, normalmente, ter a possibilidade de povoar/usar. Nesse sentido, os mapas produzidos, salvo exceções, eram encomendados ou autorizados pela Coroa e acompanhavam relatos e textos descritivos que iluminavam os aspectos principais que foram causa da sua construção. Essa intencionalidade todavia, mas que um obstáculo à análise, significa um entendimento da atividade social sobre o espaço e o próprio conhecer da base territorial que determinava a ação do agente colonizador. Fica evidente o papel do espaço geográfico, não como receptáculo, mas como elemento fundamental na dinâmica que se estabelecia.

Há, entretanto que se destacar que no vasto espaço colonial cartografado abundavam áreas anecúmenas e os pequenos pontos de parco povoamento, notadamente os estabelecidos formalmente pela Coroa (vilas para o caso do Oeste baiano), tinham uma importância 
ANDRADE, A.B. A ocupação dos sertões no século XVIII. O caso do...

exponencial no controle e uso dos seus imensos termos. Assim, antes de tratar efetivamente da evolução político-administrativa e dinâmica espacial da região, faz-se necessário esclarecer o que era e qual a tipologia desses "nós" urbanos do Brasil setecentista.

Nesse escrito, não se toma necessariamente o urbano como espaço de maior concentração demográfica ou de oferta de serviços. Para o Brasil do século XVIII, as formações urbanas eram determinantemente, núcleos de controle do território, "chaves" de acesso ao vasto espaço colonial e pontas de "tentáculos" da hierarquia da Coroa. Por esses motivos também acabavam por se constituir em núcleos de maior povoamento e passavam a exercer centralidades diversas - comercial, jurídicas, militares, eclesiásticas, administrativas, etc.

Esta tipologia de urbano só se concretizava formalmente nas cidades e vilas erigidas pelos agentes da Coroa e donatários onde se estabelecia junto à Casa da Câmara e Cadeia um corpo de oficiais e juízes, regulados por instâncias hierárquicas superiores (Governo Geral, Conselhos Reais e o próprio Rei), mas responsáveis, atrelados a outros agentes de produção do espaço, pela regulação, controle e uso do território pertencente (sede da vila ou cidade e seu termo).

Para o caso do Oeste baiano, a elevação de vilas e cidades só se deu no decorrer do século XIX, os imensos territórios, todavia, possuíam outros núcleos de povoamento com relativa densidade demográfica para aquele espaço pouco habitado, eram as aldeias, povoados, pousos, fazendas e lugares. Terminologias com diferentes significados que estavam vinculados, naquele nível de hierarquia, aos poderes das vilas existentes, estabelecidas nas suas longínquas sedes.

A ocupação era dispersa, como se pode comprovar na análise das imagens da quarta seção deste texto, e os termos das vilas se prolongavam pelos sertões (espaço a ser conhecido, ocupado, colonizado). Este fato revela a importância política do evento de erição das novas vilas, pontos nodais de controle estrategicamente escolhidos pelo donatário ou agentes da Coroa 
ANDRADE, A.B. A ocupação dos sertões no século XVIII. O caso do...

(Ouvidor ou Procurador Geral), mas também reflete as dificuldades de acesso ao Oeste, visto que os afluentes da margem esquerda do São Francisco, via regra, não possibilitavam navegação e, especialmente no trecho norte, o rigor do semi-árido e a predominância de solo ácido aplacava o desejo de fixação do colonizador. Por outro lado, os fundamentais pousos e caminhos hídricos e terrestres davam mobilidade à vida naqueles lugares, articulando-os com outras áreas povoadas, notadamente litoral e minas e induzindo à posse e estabelecimento na terra, não obstante as agruras do rigor climático e pedológico. Assim, se estabeleceram os primeiros núcleos de povoamento e sedes do urbano naquela região.

\section{Sertões, litoral e minas}

Os três termos guardam imensas generalizações e circunscrevem vastas áreas do território colonial. Trata-se como sertões o vazio interior, havendo referências desde um sertão "próximo", no entorno do Recôncavo baiano até os sertões amazônicos, para muito além dos limites de Tordesilhas; o litoral também não dizia respeito a uma continuidade homogênea, muito antes disso, era composto por pontos de povoamento dispersos pela imensa costa brasileira; da mesma forma, as "minas", ainda que tivessem uma maior concentração na Capitania de Minas Gerais, não representavam uma unidade, mas diversas áreas de exploração mineralógica do interior do Brasil, a exemplo das atuais terras da Chapada Diamantina, centro de Goiás e Mato Grosso, dentre outras.

Até por possuir grande alcance espacial esses genéricos recortes do Brasil colonial não podem ser entendidos isoladamente, especialmente se o foco for, como neste texto, o século XVIII. Ainda que tenham tido usos e períodos de ocupação diferenciados, os sertões e as minas, áreas interiores, sempre foram articulados por caminhos que os ligavam ao litoral. $\mathrm{O}$ entrelace entre essas regiões ia para além das ligações físicas, estabeleceram-se relações hierárquicas de poder e circulação de fluxos diversos configurando 
ANDRADE, A.B. A ocupação dos sertões no século XVIII. O caso do...

verdadeiras redes técnicas que, mesmo dispersas, interligavam os núcleos de povoamento interiores às cidades-capitais litorâneas.

Observando pontualmente cada uma delas, tem-se:

Numa faixa litorânea, primeiramente ocupada, formaram-se as mais densas manchas de povoamento dos séculos XVI e XVII, eram espaços, como o Recôncavo baiano, com produção voltada aos interesses coloniais de Portugal e, até por isso, vinculados a um porto/alfândega que controlava as exportações.

Os sertões, conforme escrito alhures, eram o desconhecido interior, inacessível a grande parte dos colonos, entretanto já penetrado por aventureiros em busca de metais e "drogas", especiarias a serem comercializadas no império português. À medida que se dava a expansão da ocupação da faixa litorânea e despertavam os interesses para o interior do continente - notícias de eldorados - os caminhos e pousos que cruzavam os sertões passaram a ser paulatinamente conhecidos, mapeados e ocupados.

As minas sofreram o mais abrupto povoamento dessas áreas. A descoberta de ouro, prata, diamantes e outros metais ao final dos Seiscentos e início dos Setecentos despertaram um fluxo sem precedentes na história do Brasil Colonial para o interior do território, é acintoso que ao final do século XVIII formações urbanas mineiras já estavam entre as mais densas ocupações de todo o Brasil. O historiador português Orlando Rocha Pinto afirma que

Não há nada que nos possa dar uma ligeira ideia sequer do alvoroço geral que produziu a notícia da descoberta das grandes jazidas de ouro no interior. Espalhada a notícia por todo o Brasil e no reino, as migrações em massa tornar-se-ão espantosas: das cidades, das vilas, dos recôncavos, ao fundo dos sertões, acorrerão brancos, pardos, negros, índios [...] Os lavradores partem com seus negros ou os vendem para serem levados às minas, por altos preços de que não tinham sonhado em tempo algum; emigra a gente hábil dos engenhos, feitores, mestres, purgadores, carpinteiros das caixas, e outros de ofícios necessários à indústria [da cana], que todos corriam entusiasmados à chamada da fortuna. Para as minas vão também os animais de carga, mulas, bois, cavalos, tão preciosos para os engenhos, onde eram disputados nestes por elevadas somas para transportes. (PINTO, 1987, p.111 e 116). 
ANDRADE, A.B. A ocupação dos sertões no século XVIII. O caso do...

Documentos históricos (NEVES; MIGUEL, 2007) dão pistas acerca deste "sertão de transição" entre o litoral ocupado e as minas atraentes ao olhar do migrante. Os caminhos que levavam mercadorias e escoavam produção mineradora, também se consolidavam a partir da formação de lugares permanentemente povoados a partir de pousos de tropeiros, feiras e freguesias que, entendidas pelo donatário e/ou Coroa como importantes nós na articulação entre as duas áreas, eram elevados a vilas onde se instituía o poder formal do rei, ampliando assim a possibilidade de controle sobre o território e fluxos que por ali circulavam.

Os caminhos para o transporte de gados dos currais dos sertões para as áreas mais povoadas (litoral ou minas) e as feiras decorrentes eram frequentemente referenciados em textos do século XVIII, a exemplo de uma solicitação de moradores do litoral norte de Salvador (freguesias de Santo Amaro da Ipitanga e de São Sebastião do Passé) que escreveram para o Rei solicitando intervenção nos desmandos do superintendente capitão Luiz Pereira Almeida no controle das estradas e produtos da feira de gado do Capoame (AHU, 1734). No dito documento os requerentes indicam que "vivem e morão a beira da estrada do sertão desde o eng.o da Matta de São João athé a borda da Matta", ou seja, uma área relativamente próxima do Recôncavo ocupado, entretanto, ainda assim nomeado como sertão. Também há a indicação de boiadas que vem dos sertões para serem vendidas na dita feira do Capoame. Registros de fluxos materiais e regulares que articulavam litoral e interior.

Entretanto, o acesso e ocupação do sertão, via regra, não ocorria sem animosidades com o gentio e agruras na formação de vilas, especialmente em espaços mais distantes da povoada faixa litorânea. Em meados do século XVIII, um ofício do Vice-Rei retrata o desbravamento do interior da Bahia e o contato com o indígena, o Conde dos Arcos, tratando da criação de novas vilas e nomeação de párocos para o sertão, escreve que

Embaraços taes, que se não são invenciveis, não deixão de ser dificultozas, especialmente em novos estabelecimentos, 
ANDRADE, A.B. A ocupação dos sertões no século XVIII. O caso do...

como os de que se tem tratado athé agora, em que o primeiro objecto hé a comodidade dos Indios do Brazil, gente esta, que por natureza não só hé rude, más desconfiada, por modo tal que athé para perceberem o que lhes hé mais util, e proveitozo, se necessita de jeito, e modo para se the introduzir, sem que lhe cauze a mais leve repugnancia. Não tem sido pequena a do Concelheiro Manuel Estevão de Almeida Vasconcellos Barberino de não ver se não de todo concluidas ao menos muito mais adiantadas as erecções das novas Villas, mas não obstantes as suas repetidas reprezentações, não tem sido possivel o condescenderse com o seu efficaz dezejo, porque a distancia, em que estão situadas as Aldeas dos Indios, e o não haverem de todas as individuaes informações, que erão precizas para irem munidos com as ordens necessarias os Ministros que estão destinados para as crearem em novas villas, tem feito perder algum tempo, o qual poderá ser proveitozo para o futuro, visto que não era muito facil aos mesmos Ministros das distancias para onde vão o estarem dando conta dos embaraços, ' $\mathrm{q}$ encontrassem, e esperarem as rezoluçòes para haverem de executar o que por ellas se lhe determinasse (AHU, 1758).

Este documento acentua a dificuldade de erigir vilas e estabelecer o poder formal em áreas ainda não colonizadas e ocupadas pelo gentio. Algo relativamente esperado pois na essência significa a implantação de uma nova ordem sobre a pré-existente. A ideia de ordem e justiça levada aos sertões pelos colonizadores brancos é reforçada em diversas outras fontes, a exemplo da promoção de um morador da freguesia de São Pedro do Monte, com alcance aos sertões da povoação de João Amaro, no caminho para o Oeste, para o cargo de Capitão Mor que teria a possibilidade para "prender os delinquentes, e criminosos e executar as ordens de Justiça" (ANTT, 1716). Percebe-se que mesmo antes da erição de vilas, os instrumentos e agentes de controle da Coroa atuavam no desbravamento, ocupação e uso do território, no caso dos sertões baianos, como se tratou alhures, fundamentais espaços de transição 
ANDRADE, A.B. A ocupação dos sertões no século XVIII. O caso do...

por onde circulavam os caminhos das minas e dos gados.

No ocaso do século XVII, o governador geral escreve ao rei tratando da ereção de vilas no Recôncavo e sertão da Capitania da Baía, neste documento Luis de Lancastro reforça a necessidade de "administrar justiça aquelles moradores, e castigaremse com mais facilidade os delictos" e, estabelecendo uma estratégia para ocupar os sertões com a lei de Portugal, escreve que

para o castigo dos delinquentes, e poderem com facilidade serprezos: me parece conveniente que V.Mag.e permita que nas povoaçoens do Rio de Sam Francisco se levantem algus capitaens [...], cada hum com 20, ou 25 soldados de cavallo, assim da parte desta capitania, como da de Pernambuco, para que estes corrão aquelle destricto, e aprendão os delinquentes, que para aquelles citios costumão hir homiziarse, por nelles terem o melhor seguro, o que não será havendo estes capitaens, que executem as ordens que lhe forem dos governos, e ministros, dandose a mão os da parte desta capitania, e os da de Pernambuco; porque fazendo ao mesmo tempo a delligencia em hua, e outra parte, será muito defficultozo o escaparem de ser prezos os dellinquentes; e permitindo-o V.Mag.e assim, não faltarão homens honrados naquelles citios, que assentem esta occupação levantando a sua custa estas companhias. (AHU, 1700).

Essa breve caracterização dos sertões San-Franciscanos revela, ao final dos Seiscentos, uma vasta área vagamente cartografada e conhecida, porém com linhas de entrada, normalmente seguindo leitos hídricos e caminhos de gados e, principalmente, com pontos de ocupação e controle, os povoados e vilas que iriam se constituir ao longo dos séculos seguintes.

\section{Evolução administrativa das principais formações urbanas do Oeste baiano}

O entendimento da evolução político-administrativa das unidades municipais do Oeste baiano dá pistas acerca da ocupação e estratégia de localização das principais formações urbanas da 
ANDRADE, A.B. A ocupação dos sertões no século XVIII. O caso do...

região. A emancipação política com elevação de povoados e sedes de freguesias a vilas e posteriormente a cidades foi sempre uma ação deliberada em busca da fragmentação administrativa e ampliação do controle sobre o território.

A atual mesorregião Extremo Oeste baiano, bem como a maior parte dos municípios que compõem a mesorregião do vale Sanfranciscano da Bahia, são decorrentes de uma história de ocupação formal, povoamento e uso relativamente recentes com a primeira sede de vila criada na região apenas na segunda metade do século XVIII. Daí que, nesta seção, com texto apoiado em dados da Superintendência de Estudos Econômicos e Sociais da Bahia (SEI, 2003) e da obra enciclopédica de Francisco Vicente Vianna (VIANNA, 1893), observa-se um avanço na análise dos dados para além do século XVIII, sem contudo perder o foco na formação territorial dos Setecentos. Entende-se que os processos espaciais possuem uma dinâmicas peculiares que se prolongam num tempo não necessariamente circunscrito num recorte cronológico e que eventos sucedidos em tempos pretéritos poder repercutir a médio e longo prazo na estrutura social de uma dada região.

Toda a margem esquerda do médio São Francisco, ainda que cortada por vários caminhos terrestres e fluviais ao longo do século XVIII, possuía nesse período uma ocupação político-administrativa absolutamente dispersa, chegando ao final dos Setecentos com apenas uma vila elevada - São Francisco das Chagas da Barra do Rio Grande -, ao passo que na faixa litorânea da Capitania da Bahia havia 25 vilas e a cidade capital de Salvador da Baía de Todos os Santos, seis outras vilas mais adentro do território, três em áreas mineiras uma ao norte e duas ao cento da Serra do Sincorá e, junto ao Rio São Francisco, na sua margem esquerda, mais uma vila Santo Antônio do Urubu de Cima. Certamente, do que hoje é o território baiano, a porção oeste foi a mais tardiamente ocupada.

O Além-São Francisco, na verdade, não pertenceu exclusivamente à Capitania da Bahia, didaticamente Vianna ensina que 
ANDRADE, A.B. A ocupação dos sertões no século XVIII. O caso do...

O território em que se acha a cidade [da Barra do Rio Grande], bem como todo o da margem esquerda de S. Francisco, conhecido por sertão de Rodellas, sendo primitivamente pertecente a Bahia, que o colonisou e administrou, fundando D. João de Lancastro nem só a povoação de que, como já dissemos, surgiu a actual cidade da Barra, como as outras de Campo-Largo, Pilão Arcado, etc, passou, em virtude do decreto regio de 11 de janeiro de 1715, a pertencer a Pernambuco, mas somente na parte administrativa e ecclesiastica, porquanto a judicial continuou sujeita a Bahia. mais tarde o decreto de 15 de janeiro de 1810 creou a comarca do Sertão de Pernambuco, comprehendendo a villa de Cimbres, os julgados de Garanhuns, Theresina, Riberia de Pajahú, Tacaratú, cabrobó e a villa de S. Francisco das Chagas da Barra do Rio Grande com as povoações de Pilão-Arcado, Campo Largo e Carinhanha, mandado que a villa da Barra, que até então era da correição de Jacobina, não obstante pertencer a capitania de Pernambuco, por lhe estar mais proxima do que a cabeça da comarca respectiva, ficasse na sua correição pertencendo a nova comarca. $\mathrm{O}$ decreto porém, de 3 de junho de 1820, creou nova comarca, desmembrada da do sertão de Pernambuco, denominando-a do Rio de S. Francisco, comprehendendo, como cabeça, a dita villa da Barra, e a de Pilão Arcado com as povoações de Campo Largo e Carinhanha. Esta comarca do Rio de S. Francisco, que começava no Pão da História e terminava no rio Caribuamba, foi pelo decreto de 7 de julho de 1824 desmembrada de Pernambuco e annexada a provincia de Minas, mas a resolução de 15 de outubro de 1827 desligou-a desta ultima e encorporou-a a Bahia, voltando assim este vasto territorio a primitiva possuidora depois de cento e doze annos. (VIANNA, 1893, p.424-425, grifo nosso)

Ou seja, o Sertão de Rodellas, ao longo da margem esquerda do rio São Francisco pertenceu, durante a maior parte do século XVIII à Capitania de Pernambuco, pela facilidade de acesso àquelas terras através das margens do dito rio. Foi nesse período, mais exatamente em 23 de agosto de 1753 que, respeitando a provisão régia de cinco de 
ANDRADE, A.B. A ocupação dos sertões no século XVIII. O caso do...

dezembro de 1752, foi erigida a vila de São Francisco das Chagas da Barra do Rio Grande, hoje simplesmente a cidade de Barra na mesorregião Vale Sanfranciscano da Bahia.

A localização estratégica foi fator fundamental na elevação desta vila, ela foi fundada num "entroncamento" de vias fluviais que articulava o norte e o sul através do rio São Francisco e acessava por caminhos hídricos ou terrestres as terras/minas do leste e oeste. A vila é decorrente de um arraial formado por índios pacificados a partir de orientação do então Governador Geral D. João de Lancastro ao final do século XVII. Esta medida foi tomada para evitar as invasões e ataques do gentio (Acoroazes e Mocoazes) às fazendas de gado da região. Os óbices demográficos e materiais daquelas distantes terras, porém levou ao retardo da elevação do povoado a vila, só ocorrendo depois de mais de meio século.

Após a constituição da vila, entretanto, a nova formação urbana passou a exercer uma centralidade política, administrativa, religiosa, jurídica e comercial (junto à desembocadura do Rio Grande no São Francisco) por um vasto termo só fragmentado em novas vilas no século seguinte, como se vê na Figura 1.

A observação da evolução político-administrativa do Oeste baiano permite traçar algumas considerações acerca da organização espacial daquela região no século XVIII: Uma marca da ocupação e interiorização do Brasil colonial que se confirma na região é a utilização dos corredores hidrográficos, tanto pela facilidade de acesso/orientação, como pela disponibilidade de alimentação. Se o Rio São Francisco teve um papel primordial na ocupação dos sertões, na condução dos gados e no acesso às minas, os seus três principais afluentes da margem esquerda - Cariranha, Corrente e Grande - também exerceram importante função na penetração para o Além-São Francisco e, consequentemente, no estabelecimento dos primeiros núcleos de povoamento. Na sobreposição do mapa hidrográfico da região com a sede das principais formações urbanas é possível verificar que o traçado das vias fluviais, mesmo as inavegáveis, coincide com a localização das vilas e cidades locais. 
ANDRADE, A.B. A ocupação dos sertões no século XVIII. O caso do...

Figura 1:Ordem cronológica da sequência de desmembramentos da vila de São Francisco das Chagas da Barra do Rio Grande

- 1820 - Campo Largo, atual Cotegipe

- 1890 - Santana do Angical, atual Angical

- 1962 - Brejolândia, Cristópolis e Tabocas do Brejo Velho

- 1891 - Barreiras

- 1962 - Baianópolis, Catolândia e São Desidério

- 2000 - Luis Eduardo Magalhães

- 1962 - Canápolis

○ 1985 - Wanderley

- 1832 - Cariranha

- 1866 - Nossa Senhora da Glória do Rio das Éguas, atual Correntina

- 1880 - Porto de Santa Maria da Vitória do Rio Corrente, atual Santa Maria da Vitória

- 1890 - Santana

- 1962 - Serra Dourada e Canápolis

- 1958 - Coribe

- 1989 - São Félix do Coribe

- 1985 - Jaborandi

- $1958-\operatorname{Cocos}$

- 1961 - Malhada

- 1989 - Iuiú

- 1989 - Feira da Mata

- $\quad 1840$ - Santa Rita do Rio Preto, atual Santa Rita de Cássia

- 1961 - Formosa do Rio Preto

- 1989 - Mansidão

- 1985 - Buritirama

- $\quad 1989$ - Muquém do São Francisco

Fonte: SEI, 2003.

Destaca-se a presença de apenas uma vila erigida no século XVIII para toda a região, entretanto, observando a margem direita do rio São Francisco, esse fato já não aparece tão isolado visto que em 1720 , estimulado pelas descobertas mineralógicas foi criada a vila de Santo Antônio de Jacobina e quatro anos após, em 1724, duas outras ao sul da Chapada, Santíssimo Sacramento das Minas do Rio de Contas e Nossa Senhora do Livramento das Minas do Rio de Contas. Além 
ANDRADE, A.B. A ocupação dos sertões no século XVIII. O caso do...

dessas, com função similar a da Barra do Rio Grande, foi erguida em 1745, junto a margem do São Francisco, a vila de Santo Antônio do Urubu de Cima, no lugar que hoje se encontra a cidade de Paratinga. Esses eventos, relativamente próximos temporal e espacialmente, refletem um interesse ascendente do poder formal em legitimar a ocupação e uso sobre os territórios dos sertões, especialmente quando isso significava aproximação ou viabilidade de acesso às minas.

Ainda que o fato político da emancipação só tenha ocorrido nos séculos XIX e XX para todos os municípios do Oeste baiano, no século XVIII, compondo o termo da vila de Barra do Rio Grande, as atuais sedes de cidades eram fazendas, arraiais, capelas, povoados, sedes de freguesias, etc. que já exerciam relativa centralidade nos caminhos que cruzavam tal região. Eram núcleos puntiformes ainda não elevados a vila no século XVIII, porém já ocupados e exercendo importante papel no estabelecimento dos caminhos de gado e para as minas.

As fontes documentais e secundárias sugerem uma série de atividades para as formações urbanas do Oeste baiano no século XIX que, acredita-se tem a sua gênese em tempos mais recuados nos anos Setecentos. Lavradores de mandioca, cana, fumo, milho, arroz, feijão, algodão, mineradores, criadores de gado e a existência de um comércio regular em unidades construídas ou feiras livres (inclusive com registro de contato com formações urbanas de Minas Gerais e Goiás), certamente constituem atividades que se intensificaram com a ampliação da ocupação e dos fluxos na região, mas que tem a sua origem em tempos mais remotos o que sugere uma demarcação do território por agentes privados ou religiosos antes da presença formal da Coroa. Esse fato está presente na análise acerca da origem dos municípios feitos por Viana (1893) e é visível na leitura da cartografia histórica que se fará a seguir.

\section{Análise de mapas históricos}

Já se abordou anteriormente a importância da cartografia histórica para a pesquisa sustentada na Geografia histórica, trata-se 
ANDRADE, A.B. A ocupação dos sertões no século XVIII. O caso do...

de um documento fundamental para $o$ entendimento de determinada configuração espacial pretérita. Mapear significa conhecer o território, os mapas históricos, especificamente, são verdadeiros instrumentos de comunicação, posse e estratégia territorial, considerando as imprecisões e intencionalidades, a cartografia revelava a configuração territorial em um dado recorte temporal, não é por um acaso que a "missão" de mapear o espaço colonial era restrito a alguns poucos indivíduos.

O resultado estático do desenho apresenta indícios e marcas de uma dinâmica vivida no espaço geográfico. Cores, linhas e nomes se articulam mostrando formações urbanas hierarquicamente distribuídas, caminhos terrestres, rede hidrográfica, base orográfica, engenhos e regiões geográficas, elementos que compõem estruturas espaciais pretéritas e que, em determinado momento, foram interpretados e desenhados numa escala imprecisa aos olhos do cartógrafo revelando substratos dinâmicos que tanto sustentavam como induziam ações no território ocupado.

Os dois mapas apresentados a seguir (Figuras 2 e 3 ) produzidos no decorrer do século XVIII são documentos fundamentais na análise espacial da região do Além-São Francisco nos Setecentos, inclusive porque, para o período, há poucos registros cartográficos da região, especialmente em grandes escalas que permitam uma análise mais detalhada, essa escassez parece evidente se considerarmos que ao longo do referido século as áreas mineiras e fronteiriças concentravam as atenções dos agentes da Coroa e, consequentemente, a cartografia produzida tendia a focar esses espaços, mesmo em detrimento do litoral mais densamente ocupado, porém já mapeado e conhecido nos séculos anteriores.

A Figura 2, de autoria do cartógrafo francês Jacques Nicolas Bellin, foi desenhada em 1754 (dois anos após a elevação de Barra do Rio Grande a vila). Há um claro destaque às informações da faixa litorânea, desde o Rio de Janeiro até a baía de Todos os Santos; porém a pequena escala e não permite um detalhamento de áreas mais densamente povoadas para a época, a exemplo do Recôncavo baiano. 
ANDRADE, A.B. A ocupação dos sertões no século XVIII. O caso do...

Figura 2: Suíte du Bresil: depuis la baye de tous lês Saints jusqu'a St. Paul, 1754

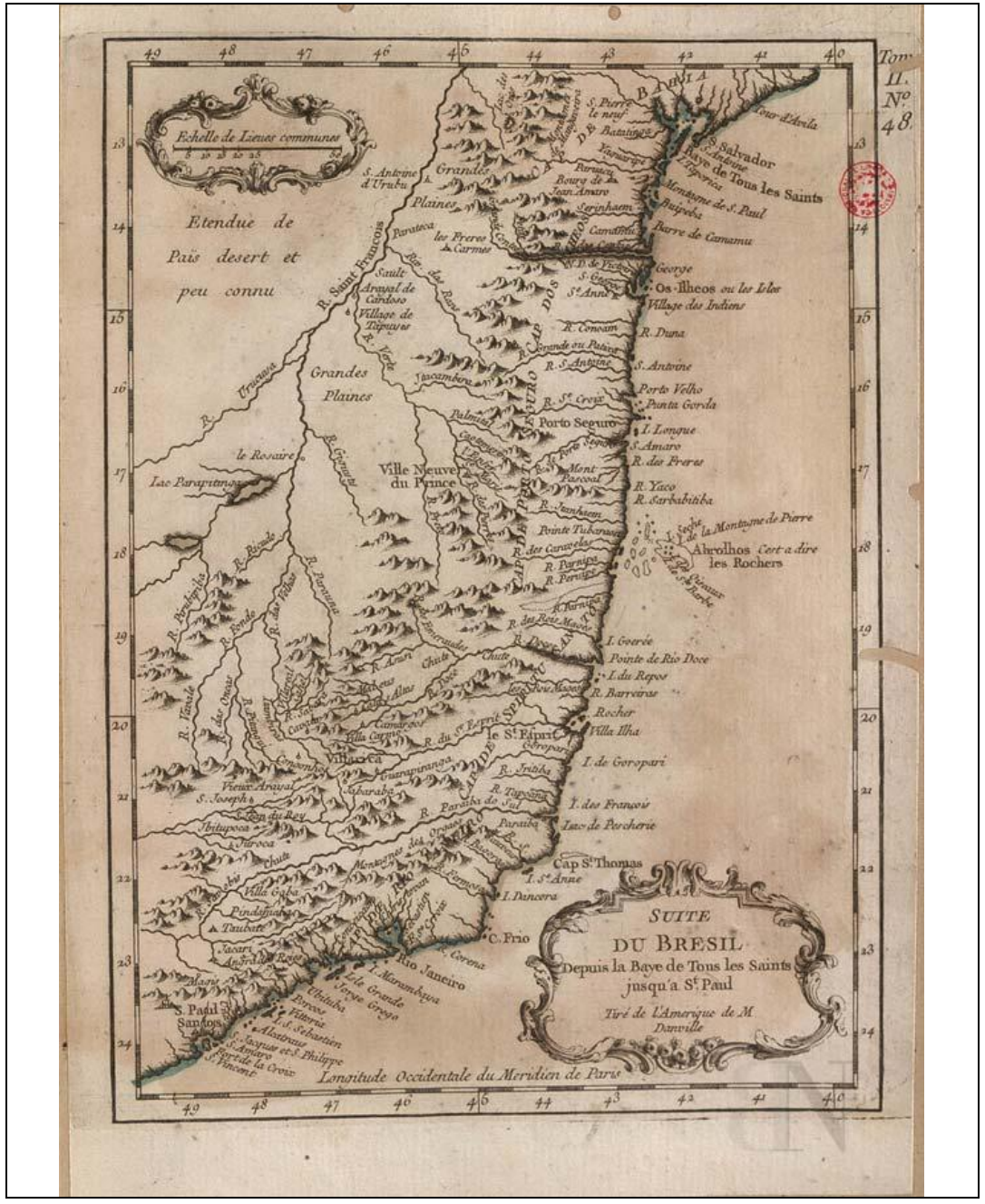

Fonte: Biblioteca Nacional Digital (BELLIN, 1754) 
ANDRADE, A.B. A ocupação dos sertões no século XVIII. O caso do...

Contrastando com o litoral bem ocupado e mapeado, está o sertão a ser desbravado. Alguns elementos físicos determinantes na interiorização da ocupação estão presentes no mapa a exemplo das bacias hidrográficas do leste com a preciosa indicação das principais vias fluviais de entrada e as barreiras orográficas que acompanham paralelamente a faixa da orla marítima e se apresentam como obstáculos à penetração e, consequentemente, como limites entre o ocupado e o desconhecido, ou melhor, o espaço a ser colonizado.

Em relação ao Oeste, a ausência de dados já é a primeira informação sobre a região, que nesse momento, meados dos Setecentos, possuía uma parca ocupação. Corroborando com essa apreensão, o autor explicitamente indica que a porção para além do rio São Francisco é uma "etendue de Pais desert et peu connu", de fato, se não era povoado e conhecido, não havia como ser mapeado, ressalva-se que este despovoamento era apenas relativo, visto que, já havia pontos de ocupação (fazendas, povoados, pousos e caminhos), ainda imprecisos e por isso de difícil registro cartográfico. O que não exime o autor da lacuna de conhecimento sobre o território, visto que a vila de Barra do Rio Grande já havia sido criada um pouco mais a norte da área mapeada e os importantes afluentes da margem esquerda do rio São Francisco (rio Grande, Corrente e Cariranha) também são ignorados.

Destaca-se ainda o registro da vila de Santo Antônio do Urubu e a centralidade do rio São Francisco no conjunto do desenho e, certamente, do território cartografado, correndo pelo interior paralelamente à faixa marítima e estabelecendo conexões entre as minas do centro-sul e o litoral nordestino.

A Figura 3 é um recorte da Carta Geral do Brasil datada de 1798 feita pelo matemático e futuro governador do Espírito Santo (em 1801) Antônio Pires da Silva Pontes Leme. Além da carta, há cinco outros mapas em escala maior que contemplam Recife, Baía de Todos os Santos, Baía da Guanabara, Cabo Frio e Barra do Rio Grande do Sul, é curioso observar que no quinto desenho há o crédito do levantamento dos dados, em 1779, ao Brigadeiro 
ANDRADE, A.B. A ocupação dos sertões no século XVIII. O caso do...

Engenheiro José Custódio de Sá e Faria, dezenove anos antes da publicação.

Apesar de também ser um mapa em pequena escala, a sua ampla constituição e o maior conhecimento do território ao final do século XVIII permite uma riqueza de detalhes pouco provável em registros anteriores, especificamente em relação aos caminhos terrestres que demarcam verdadeiras linhas de penetração ao território colonial.

Em relação ao povoamento, o próprio destaque dado pelo autor com os cinco desenhos anexos supracitados já revela um dado evidente que é o maior adensamento de vilas, engenhos e povoados no litoral, havendo uma dispersão para o oeste, a exceção das áreas mineiras.

No mapa é possível confirmar a pertença à Capitania de Pernambuco da longa faixa a oeste do rio São Francisco até a Capitania de Goiás, o que compunha o já referenciado Sertão de Rodellas. Em relação à região aqui estudada, apesar de existirem algumas ausências e equívocos na Figura 3 - o que denota a dificuldade de informações sobre a área - os dados apresentados confirmam a documentação primária e acrescentam novos indícios, é possível destacar: a presença da vila de Santo Antônio do Urubu como importante entroncamento no médio-alto São Francisco; o registro da vila de São Francisco das Chagas da Barra do Rio Grande, ainda que posto na margem direita e com o nome incompleto; transparecendo a dificuldade de acesso e o desconhecimento do território, os rios da margem esquerda do São Francisco são escassamente mapeados e possuem equívocos no traçado, o único identificado é o Cariranha que está mais ao sul, próximo às minas; é significativo observar a riqueza de informações e densidade de ocupação no sul da Capitania do Maranhão e nas Capitanias de Minas Gerais e Goiás, neste caso, diretamente associado à atração mineira; enfim, revela-se também na Figura 3, além das naturais vias fluviais, os espaços coloniais (litoral, minas, sertões) articulados por caminhos terrestres que cruzam ou margeiam o Oeste baiano, destacando-se a centralidade da vila de 
ANDRADE, A.B. A ocupação dos sertões no século XVIII. O caso do...

Barra do Rio Grande acessível pelo caminho que margeia o rio São Francisco, mas também por caminhos oriundos de Cachoeira, no Recôncavo baiano; há o registro de dois povoados, não identificados, entre Urubu e Barra, formando uma linha à direita do Oeste, possivelmente onde hoje se encontra a cidade de Ibotirama e, deste caminho paralelo ao São Francisco sai uma estrada cortando a região em direção à Capitania de Goiás, passando, aproximadamente, onde adiante se constituiria a vila de Barreiras.

Figura 3: Carta geographica de projeção espherica ortogonal da Nova Luzitânia ou América Portuguesa e Estado do Brazil, 1798

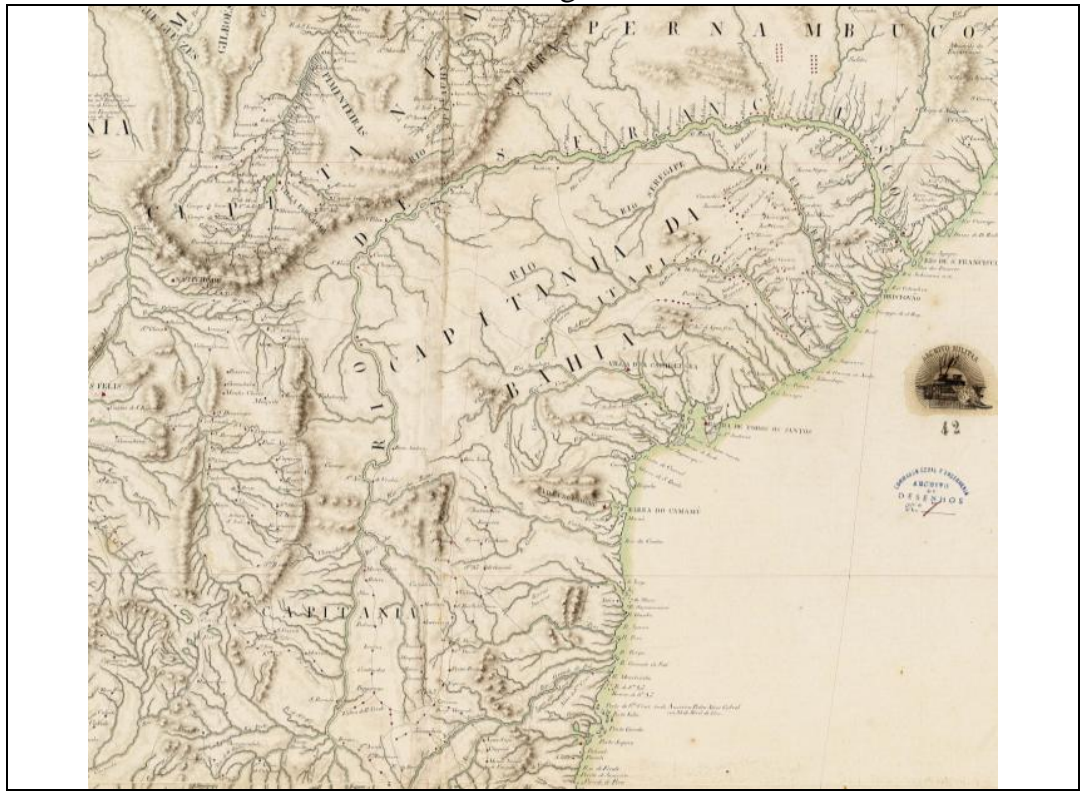

Fonte: Mapoteca do Exército Português (LEME, 1798)

\section{Considerações finais}

$\mathrm{O}$ volume de documentação existente e ainda carente de transformação em texto histórico se apresenta como estímulo aos estudos vindouros, mas também prepara armadilhas às pretensas 
ANDRADE, A.B. A ocupação dos sertões no século XVIII. O caso do...

conclusões de agora. O labor na pesquisa primária ensina que novos grupos de documentos podem permitir outras avaliações acerca de cenários já traçados. Desta forma, ratifica-se que o texto que aqui se apresentou, sustentado em fontes secundárias e primárias (escritas e cartográficas), revelou muito objetivamente os primórdios da ocupação e uso das terras da margem direita do médio São Francisco, boa parte delas circunscritas na região do Oeste baiano, fez-se isso apoiado no arcabouço teórico-conceitual da Geografia Histórica e priorizando dados do século XVIII, quando aparecem os primeiros registros efetivos de colonização daquelas terras. É fundamental esclarecer que a dimensão do texto permite apenas a apresentação de dados documentais e breves análises acerca de outros escritos o que sugere brechas a serem ocupadas com novos estudos que avancem, por exemplo, na avaliação dos agentes de produção daquela região, ou na gênese do urbano para aquele tempo e espaço.

Concretamente tem-se dados irrefutáveis sobre a constituição e evolução político-administrativa da região, a exemplo da a elevação de apenas uma vila ao longo do século XVIII com um imenso termo que ocupava todo o território do que hoje se conhece como mesorregião do Extremo Oeste baiano. Esse território foi fragmentado em oito novas vilas ao longo do século XIX e, só no século XX sofreu os desmembramentos que resultaram na sua atual configuração política. É também evidente o parco povoamento e ocupação desse espaço nos anos Setecentos, ao passo que o litoral e área mineira já possuíam um relativo adensamento demográfico, este vazio compunha o genérico e desconhecido "sertão".

Outras considerações podem ser traçadas à luz dos indícios da documentação apresentada:

(1) A falta de registros cartográficos na média e pequena escala não significa necessariamente que não havia ocupação na área, uma cartografia em grande escala poderia revelar a existência de agentes da colonização "dividindo", por vezes de forma conflituosa, o território ocupado pelo gentio principalmente com o 
ANDRADE, A.B. A ocupação dos sertões no século XVIII. O caso do...

estabelecimento de fazendas, com a lavoura e o gado, e pousos para os caminhos que inevitavelmente começavam a cortar a região;

(2) Sobre os caminhos, é possível perceber uma malha reticular formada por vias hídricas e terrestres, ainda não completamente reveladas pelos documentos consultados, que articulavam os pontos de maior povoamento, e permitiam, segundo aquela temporalidade específica, ligações e pleitos ao poder formal que, ao longo do século XVIII e mais decisivamente no século XIX, lá se estabeleceu com a criação das suas bases locais, as primeiras vilas;

(3) A dispersão da produção pecuária ao longo dos rios e a atração ao interior produzido pela notícia da descoberta de metais preciosos certamente foram os dois principais motivos da ocupação das terras para oeste do rio São Francisco, o dito rio cruza o imaginário polígono já citado entre as terras do centro da Bahia, a Capitania de Goiás e a de Minas Gerais. Um longo território inóspito a ser transpassado no estabelecimento de vínculos entre espaços de mais denso povoamento;

(4) O que aparece mapeado (caminhos, fazendas, vilas,etc.) faz parte de um processo de produção do espaço que possui, por vezes, longa existência temporal. Daí a necessidade da "leitura" dos dados e cartografia levando em conta a dinâmica do espaço geográfico: o que se registra pontualmente pode ter existência e sentidos anteriores.

A leitura que se fez da produção do espaço do Oeste baiano no século XVIII não se esgota nesse texto e, principalmente, não tem fim em si mesmo, acredita-se entretanto que o encontro com outros estudos de diversos "encaixes" disciplinares, possibilita o entendimento muito mais amplo desta dinâmica região baiana da atualidade. 
ANDRADE, A.B. A ocupação dos sertões no século XVIII. O caso do...

\section{Referências bibliográficas}

AHU (Arquivo Histórico Ultramarino). Feira de Gado do Capoame. Projeto Resgate, Baía, Fundo Avulsos, Doc. 4336. Lisboa/Portugal,1734.

AHU (Arquivo Histórico Ultramarino). Officio do Vice Rei Conde dos Arcos para Sebastião José de Carvalho e Mello, communicando-lhe novas informações, acerca dos Jesuítas, da Creação das novas Villas, da nomeação dos parochos para o sertão, etc. Baía, Fundo Castro de Almeida, Doc. 3738 e 3739. Lisboa/Portugal, 10 de dezembro de 1758.

AHU (Arquivo Histórico Ultramarino). Carta do Governador Geral informando sobre a necessidade de criar o posto de Juiz de Fora nas vilas de Cachoeira, São Francisco de Sergipe do Conde e Jaguaripe. Baía, Fundo Luiza da Fonseca, Doc 4320. Lisboa/Portugal, 1700.

ANTT (Arquivo Nacional da Torre do Tombo). Carta do Capitão-mor da freguesia de S.Pedro do Monte, cujas distâncias confinam com o Pará, Macarás e povoações de João Amaro, distritos da Cachoeira. Código de referência PT-TTRGM/C/51426. Cota: Registro Geral de Mercês, D.João V, liv.8, fl.405. Lisboa/Portugal, 07 de dezembro de 1716.

BELLIN, Jacques Nicolas. Suíte du Bresil: depuis la baye de tous lês Saints jusqu'a St. Paul. Biblioteca Nacional Digital/Mapoteca, 1754. Cota ARC.010,12,039.

LEME, Antônio Pires da Silva Pontes. Carta geographica de projeção espherica ortogonal da Nova Luzitânia ou América Portuguesa e Estado do Brazil. Mapoteca do Exército Português / Divisão de Infra-Estrutura, 1798. Cota 9994-3-38-52 (DSE) - CRT $281 / 2003$ 
ANDRADE, A.B. A ocupação dos sertões no século XVIII. O caso do...

NEVES, Erivaldo Fagundes; MIGUEL, Antonieta (orgs.). Caminhos do Sertão. Ocupação territorial, Sistema Viário e Intercâmbios Coloniais dos Sertões da Bahia. Salvador: Editora Arcádia, 2007.

PINTO, Orlando da Rocha. Cronologia da Construção do Brasil 1500-1889. Lisboa: Livros Horizonte, 1987.

SEI (Superintendência de Estudos Econômicos e Sociais da Bahia). Evolução territorial e administrativa do Estado da Bahia: Um breve histórico. Salvador: SEI, 2003, CD Room.

VIANNA, Francisco Vicente. Memória sobre o Estado da Bahia. Salvador: Typografia e Encadernação do diário da Bahia, 1893.

Recebido em abril de 2013 Aceito em julho de 2013 